\title{
Cognitive Levels in Saudi EFL Teachers' and Textbook Questions
}

\author{
Abdulaziz Ibrahim S. Alnofal \\ College of Languages and Translation, Al-Imam Mohammad Ibn Saud Islamic University, KSA
}

\begin{abstract}
This study aimed to investigate the thinking levels of questions asked by EFL instructors for first year English Department students at Al-Imam Mohammad ibn Saud Islamic University (IMSIU).The study also aimed to analyze the cognitive levels of the comprehension questions demonstrated by the reading and writing textbook (Unlock, Reading and Writing 1) taught for first year English Department students at IMSIU. In addition, the study examined the extent to which the instructors' questions and the book they taught differ in the proportions of lower- and higher- thinking level questions. The sample of the study consisted of 15 reading and writing classes taught by EFL instructors. Furthermore, all of the questions in the textbook (Unlock, Reading and Writing 1) were classified according to the Revised Bloom's taxonomy (Anderson et al., 2001). Descriptive and inferential analysis was used to analyze the data. Furthermore, Chi $\chi 2$ cross tabulation was used to show the differences among the levels of thinking in the two textbooks. The findings showed that the majority of the first year teachers' questions are lower-cognitive levels (knowledge, comprehension and application). Furthermore, the results of the textbook analysis also showed that there was a tendency towards lower-level cognitive skills in the two textbooks under the study.
\end{abstract}

Index Terms - cognitive level, teacher questioning, textbook questions

\section{INTRODUCTION}

Traditionally, teachers tended to dominate the interaction and speak most of the time because they thought they were able to have a control over the classroom interaction and their students' responses as well, and this would help them to achieve their instructional goals and to avoid any unpredictable behavior. Nowadays, the new generation demands instructors to bring new methods of teaching that enhance and stimulate students' learning such as questioning. The art of questioning is considered as one of the most effective and motivating tools for the teacher. Good questions are educative and they serve as means of organizing knowledge. One way for enhancing the quality of classroom questions was identifying the intellectual level of teacher questions. Questions were classified into two cognitive categories: lower order and higher order. Therefore, this study explored textbook and teachers' questions in light of Bloom's Taxonomy.

\section{LITERATURE REVIEW}

It is important to find ways to challenge students' thinking. Beyer (1997) stated that asking higher-level questions is one of the most common practices and best techniques that teachers can use to stimulate students' thinking. Questioning is an intellectual experience that calls for a response, including both problems and projects, as stated by Sanders (cited in Newton, 1978). Teachers can use questioning strategies to foster deeper thinking in their students. These questions should be clear, accurate, relevant, and logical (Paul \& Elder, 2001). Dewey (1933) stated that asking effective questions lies at the heart of successfully teaching thinking skills.

The analysis of classroom interaction shows that teacher's questions are evaluative and supportive in that they raise students' deeper thinking. Moreover, it also engages students in higher-level roles. As Chin (2006, p. 1336) highlights, teachers' questions evoke students to "formulate hypotheses, predict outcomes, brainstorm ideas, generate explanations, make inferences and conclusions, as well as to self-evaluate and reflect on their own thinking." By questioning, the teacher provides conceptual and linguistic scaffolding.

Teachers' questions can also be considered a major tool for formative assessment. Black and Harrison (2001) sate that as teachers ' questions can affect students' thinking and brainstorm their ideas, both the content of the questions and feedback, become important. Therefore, teachers need to think about how questions can be constructed and used to develop students' learning.

\section{EFFECTS OF HIGHER-LOWER COGNITIVE LEVELS}

Questioning is a techniques of thinking instruction but not all questions can be counted as thinking questions (McTighe, 1985). Swartz and Perkins (1989) claim that asking higher level questions will promote thinking skills rather than asking for simple recall. However, if students are expected to analyze or evaluate information, then they must be engaged in higher-level questioning (Hunkins, 1995). Therefore, the types of questions used in the classroom depend on the purpose of the lesson. Gall (1984) also synthesized the research on teachers' questioning and found that the factual 
questions are more effective for young students' achievement whereas the higher level questions are more effective for older students or students of high ability. Therefore, teachers who use factual questions with young students should also include some higher cognitive questions to foster advanced thinking (Elijah \& Legenza, 1978).

Some studies (Al-Kaleefah, 1996; Wilen, 1991) have indicated that most teachers spend most of their time asking low level questions which concentrate on factual information. It is assumed that such questions limit learners' critical thinking and deep understanding of the material. On the other hand, Brualdi (1998) suggested that high level cognitive questions which require students to employ higher thinking skills enable teachers to make sure whether a student has truly internalized a concept.

Costa and Lowery (1989) suggested that when teachers use terms such as "predict," "compare," "conclude," and "hypothesize" in their questions, these may also encourage students" thinking skills. Chin (2004) found that teachers believed that they had to focus on asking open-ended questions in order to give students opportunities to develop their thinking skills. But open-ended questions were not the most frequently asked questions during classroom discourse. The researcher also suggested that asking more questions does not necessarily guarantee higher level thinking; rather, the types of questions asked were the most important factor in influencing the level of thinking operations attained by students.

Several studies that dealt with analysis of teachers' questions via Bloom's taxonomy show that there is a lack of higher-level questions inside classrooms. All studies reviewed by the researcher showed the predominance of lower level questions in the teachers' questioning studies (Tan, 2007; Khan and Inamullah, 2011; Sardareh and Saad, 2013). Furthermore, studies that dealt with analysis of questions in textbooks via Bloom's taxonomy show that there is a lack of high-level questions and prevalence of low-level questions in the majority of textbooks. The predominance of lowerlevel questions in textbooks appears to be a worldwide problem. The list of studies that follows all agreed on the fact that all books they analyzed showed predominance of lower-level questions (Alul, 2005; Khan \& Inamullah, 2011; AlKhataybeh \& Al-ja'freh, 2012; Shen ,2012; Sardareh \& Saad, 2013; Toni \&Parse, 2013;)

The results of these studies indicated that most questions emphasized the knowledge or the comprehension levels. The results also indicated that possibly it is easier for teachers and authors to write lower cognitive level questions than questions on higher level. It seems that the authors who write textbook questions do not pay attention to develop the students' thinking and they found it easier to write lower level questions than higher level. Possibly, the learners for whom the questions were directed to were unable to deal with higher-level demands.

\section{THE PROBLEM}

The researcher noticed that the students' responses to the teachers' questions are limited because of some teachers' traditional teaching method of asking questions. The researcher also noticed that some of these questions are considered unclear and irrelevant questions which affect the students' learning process. Moreover, the researcher noticed that a lot of the university instructors ask questions that are factual and procedural which do not help students increase autonomy. The researcher feels that there might be a mismatch between the questions of the textbook and the questions asked by their teachers. Therefore, the researcher analyzed the questions asked by EFL teachers according to the thinking levels. Furthermore, this also evoked the researcher to analyze first year reading and writing textbook at IMSIU, and to investigate the degree to which the book helps the teacher improve students' thinking, and the degree to which it enhances students to use the different levels of intellectual processes for developing suitable thinking skills.

\section{PURPOSE OF THE STUDY}

This study aimed to investigate the levels of questions asked by EFL teachers for first year students in the English department at IMSIU. The study also aimed to classify the comprehension questions, in Unlock 1, in light of their level of thinking according to the revised Bloom's taxonomy (Anderson et al., 2001). Moreover, the study aimed to examine the extent to which the textbook (Unlock Reading and Writing 1) and the teachers' questions) differ in the proportions of lower- and higher- level questions. In other words, the study aimed at answering the following research questions:

1. What proportions of the Level one, male EFL instructors' questions in the English department at IMSIU are at lower and higher levels of thinking according to Bloom's Taxonomy?

2. What proportions of the questions in the textbook Unlock Reading and Writing 1,taught for level 1 students in the English language department at IMSIU, are at lower levels and higher levels of thinking according to Bloom's Taxonomy?

3. Do the questions in the textbook Unlock 1 taught for level 1 student in the English language department at IMSIU and the male EFL instructors' questions for level 1 students differ in the proportions of lower- and higher- level thinking levels?

\section{SIGNIFICANCE OF THE STUDY}

This study intended to investigate classroom interactions in terms of questions asked by the teacher. It also investigated the consistency between teachers' questions and the questions in the book they taught. The current study presents with important recommendations for teachers, teacher trainers and all of those who are indulged EFL teaching 
in Saudi Arabia. Moreover, the findings from this study help educators become more aware of Saudi University Freshman English language textbook selection criteria and the rationales underlying these criteria. Overall, the study serve to better enable educators to make decisions about curriculum in light of their educational purposes and goals. The results of research about levels of thinking in textbook questions can be an important factor used by textbook selection committees. Finally, as long as the researcher is concerned, the current study is the first to explore the target issue at the college level in Saudi Arabia.

\section{METHOD}

\section{A. Design of the Study}

This study is based on a descriptive research, where the researcher intended to investigated a specific phenomenon. The study used content analysis to investigate the proportions of the reading comprehension questions in the textbook Unlock, reading and Writing 1 and in 15 teachers' class questions according to Bloom's Taxonomy cognitive levels.

\section{B. Sample of the Study}

The population of the study consisted of 15 classes for different teachers who were teaching first year students English in the Department of English Language and Literature at IMSIU, during the second semester of the academic year 2016-2017.

\section{Selection of the Questions}

The textbook under study was: Unlock, Reading and Writing 1. The textbook was taught for first year students at the English Language and literature department at IMSIU in the second semester of the academic year 2016-2017. All of the questions in Unlock 1were incorporated. The total number of questions obtained from the book and from the teachers classes were 481 questions, which is considered a reasonable and manageable number. To avoid the confusion in the process of classification, questions in the textbook and those elicited from the attended sessions were numbered in a serial manner. For instance, teachers' questions were numbered from 1 to 294. This serial number was employed in the question analysis sheets. In addition, questions in (Unlock 1) were numbered in separate sheets from 1 to 187. Furthermore, The researcher attended English language classes only in level one at the English Language and literature department IMSIU in the second semester of the academic year 2016-2017.All Teachers' questions were recorded and then analyzed. The researcher classified Teachers' questions by using Bloom's Taxonomy. The total number of questions was 294 questions, which is considered a reasonable and manageable number. The number of questions was determined according to the cognitive domains of Bloom's Taxonomy.

\section{Instruments}

The researcher used two observational instruments to collect teachers' questions at Imam University, a recorder (Audio-taping), it helped the researcher to record teachers' questions in order to be transcribed later on. The other instrument was note-taking, which served as a tool to help the researcher to divide teachers' questions according to Blooms' Taxonomy.

\section{E. Content Analysis}

The researcher classified and evaluated Teachers' questions and the questions obtained from Unlock reading and Writing 1 by using Bloom's Taxonomy. Bloom's definitions of different levels were carefully studied . Bloom's taxonomy includes the six levels from the knowledge to synthesis and evaluation. Bloom's taxonomy was labeled as: knowledge, comprehension, application, analysis, synthesis and evaluation. An observation sheet was developed by the researcher for the study and used for encoding the data. The transcribed questions were then analyzed in light of question levels of thinking according to Bloom's Taxonomy. The researcher observed 15 classes of both native and non-native teachers, and analyzed their questions according to the types and levels of Bloom's Taxonomy.

\section{F. Validity of the Analysis}

To create the validity of analysis, the researcher defined concepts operationally and formatted the criteria for analyzing teachers' and textbook questions. The researcher consulted a jury of language professors and they all agreed on the validity of the procedure.

\section{G. Reliability of the Content Analysis}

Two procedures were used to determine the reliability of the content analysis. The first procedure was concerned with selecting the adequate raters for questions analysis. The second procedure was the inter- and intra-rater agreement which was employed to determine the degree of agreement among the three raters. Prior to the actual classification of data, a group of 25 questions was selected randomly and classified by the two raters including the researcher. Each rater was required to read teachers' questions and then categorize each question in one of the subcategories of the six cognitive levels. Furthermore, the raters this time were encouraged to make use of the materials they had received in the classification process. After independent classification was made, the three raters compared the results and debated the rationale for each classification and they all agreed on twenty one of twenty five categorizations $84 \%$ agreement. An 
inter-rater reliability of $80 \%$ or above was required of the raters before they became involved in analyzing the actual data. Based on the obtained agreement ratio, there was no need for additional training sessions to raise the level of interrater reliability, and hence the researcher considered the procedure of this study reliable.

\section{H. Data Analysis}

After collecting the data from the source textbook and from the classroom observations, the researcher listened to the recorded lectures, classified the questions that are related to the classroom content and were asked by the teachers. An analysis sheet was developed by the researcher for the study and used for encoding the data. The transcribed questions were then analyzed in light of question levels of thinking according to Bloom's Taxonomy. The same questions were then grouped into higher-level questions or lower level ones. After confirming the level of the questions, questioning data were recorded onto a questioning chart regarding question types (higher-order or lower-order); Levels of Higherlower Cognitive levels from the chart were summed. After each level was calculated, the total number of question levels (i.e., Knowledge-Comprehension-Application-Analysis-Synthesis-Evaluation) was divided by the number of questions the teacher or the textbook asked. This information provided a percentage in order to present a holistic view of what types of questions the teacher asked.

\section{RESULTS AND DISCUSSION}

The major purpose of this study was to analyze and compare the cognitive levels of Unlock Reading and Writing 1 and teachers' questions found in the first year of the English language and Literature Department at IMSIU. Results from the data were subjected to descriptive analyses. The descriptive analyses included the classification of teachers' questions across the cognitive levels of Bloom's Taxonomy. These data were presented in tabular forms and potted on bar graphs.

\section{A. Results Related to the First Question}

The first research question was "What proportions of the comprehension questions in Unlock Reading and Writing 1 and in male EFL instructors' questions in the English department at IMSIU are at lower levels and higher levels of thinking according to Bloom's Taxonomy?" To answer this question, the researcher analyzed 294 questions in Unlock Reading and Writing 1 according to the Bloom's Taxonomy of educational objectives (cognitive domain). The researcher also analyzed 294 questions recorded in 15 English classes for the instructors on Level one classes in the English Department at IMSIU. The textbook under and the teachers showed varied numbers of questions as follows: Textbook questions One included 294 questions, Teachers' questions included 187 questions. 481 questions were obtained from the two textbooks. Table (1) presents the data.

TABLE 1:

FREQUENCIES AND PERCENTAGES OF COMPREHENSION QUESTIONS ACCORDING TO BLOOM's TAXONOMY OF EDUCATIONAL OBJECTIVES IN TEXTBOOK QUESTIONS AND TEACHERS' QUESTIONS

\begin{tabular}{|llll|}
\hline Level & Statistic & Textbook Questions & Teachers' Questions \\
\hline \multirow{2}{*}{ Knowledge } & Count & 59 & 7 \\
\cline { 2 - 4 } & Percentage & $20.08 \%$ & $3.74 \%$ \\
\hline \multirow{2}{*}{ Application } & Count & 179 & 119 \\
\cline { 2 - 4 } & Percentage & $60.88 \%$ & $63.63 \%$ \\
\hline \multirow{2}{*}{ Analysis } & Count & 19 & 5 \\
\cline { 2 - 4 } & Percentage & $6.46 \%$ & $2.67 \%$ \\
\hline Synthesis & Count & 10 & 14 \\
\cline { 2 - 4 } & Percentage & $3.40 \%$ & $7.48 \%$ \\
\hline Evaluation & Count & 0 & $0.53 \%$ \\
\cline { 2 - 4 } & Percentage & $0 \%$ & 41 \\
\hline Total & Count & 27 & $21.95 \%$ \\
\cline { 2 - 4 } & Percentage & $9.18 \%$ & 481 \\
\hline
\end{tabular}

The analysis of the cognitive levels of the comprehension questions shows a significant relation between the textbook and teachers' questions as shown in table (1). It is noticed that the majority of the questions in the two sources with percentages of $(60.88 \%$ and $63.63 \%)$ respectively. An important result was that no question was categorized under the level "synthesis". Similarly, only one question appeared under the level synthesis in Unlock $1(.53 \%)$.

Table (1) also indicates that the questions were presented in the following order according to their inclusion in Unlock 1: (Comprehension, knowledge, evaluation, application, analysis, and synthesis), whereas in teachers 'questions the order was (Comprehension, Evaluation, analysis, knowledge, application, and synthesis). It can also be noticed from the data shown in table (1) that the majority of the questions in the two textbooks appeared under the level "comprehension", whereas the level "synthesis" was almost neglected in teachers' questions and completely neglected in Unlock One.

B. Results Related to the Second Question 
The second research question was "Do teachers' questions and questions in Unlock Reading and Writing 1 differ in the proportions of lower- and higher- level questions?"

Frequencies of the questions included in the two sources under the study were calculated according to Bloom's Taxonomy Thinking Levels (low-level questions and high-level questions). The percentages of the questions among the two levels in each source were calculated. The data are presented in table (2).

TABLE 2:

FREQUENCIES AND PERCENTAGES OF LOWER- AND HIGHER- LEVEL QUESTIONS IN TEACHERS' CLASSES AND ONE AND UNLOCK 1 TEXTBOOK

\begin{tabular}{|c|c|c|c|c|}
\hline Thinking Level & Statistic & Low & High & Total \\
\hline \multirow[t]{2}{*}{ Teachers' Questions } & Count & 257 & 37 & 294 \\
\hline & Percentage & $87.42 \%$ & $12.59 \%$ & \\
\hline \multirow{2}{*}{$\begin{array}{l}\text { Unlock } 1 \text { Reading and } \\
\text { Writing }\end{array}$} & Count & 131 & 56 & 187 \\
\hline & Percentage & $70.06 \%$ & $29.94 \%$ & \\
\hline
\end{tabular}

Table (2) shows that there is a tendency towards lower- level cognitive skills in the two sources under study. When moving from teachers' questions to textbook questions an incline is noticed in the percentage of the lower-level questions and an increase is noticed in the percentage of the higher-level questions. Table (2) also shows that low level questions are dominant in the two sources with percentages of $87.42 \%$ for teachers' questions, and $70.06 \%$ for textbook questions. On the contrary, higher-level questions appeared in a relatively low percentage in the two sources (Teachers' questions: 12.59\%; Unlock Reading and Writing 1: 29.94\%). Moreover, the statistical procedure of Chi Square ( $\chi 2)$ cross tabulation was used to determine whether the questions in the two sources under study differ in the proportions of lower-and higher-level questions. Table (3) presents the data.

TABLE 3:

RESULTS OF X2 TEST OF INDEPENDENCE

\begin{tabular}{|llllll|}
\hline & Value & Df & $\begin{array}{l}\text { Asymp. Sig. (2- } \\
\text { sided) }\end{array}$ & $\begin{array}{l}\text { Exact Sig. (2- } \\
\text { sided) }\end{array}$ & $\begin{array}{l}\text { Exact Sig. (1- } \\
\text { sided) }\end{array}$ \\
\hline Pearson Chi-Square & $22.090 \mathrm{a}$ & 1 & .000 & & \\
\hline Continuity Correctionb & 20.991 & 1 & .000 & .000 \\
\hline Likelihood Ratio & 21.575 & 1 & .000 & .000 & .000 \\
\hline Fisher's Exact Test & & & & & \\
\hline N of Valid Cases & 481 & & & & \\
\hline
\end{tabular}

a. 0 cells $(.0 \%)$ have expected count less than 5 . The minimum expected count is 36.16 .

b. Computed only for a $2 \times 2$ table

Table (3) indicates that Chi Square computed value was 22.090 with a freedom degree of 1 . The significance value was 0.000 which is less than 0.05 and less than 0.01 . Since the significance value is less below 0.05 , this means that it is statistically significant value. Thus the statistical answer for the second research question is: Yes, Teachers' Questions and Questions in Unlock 1differ in light of the percentages of the high- and low- level questions. Although the answer for the question seems clear without the need for Chi Square formula, it is more accurate when significance differences are statistically and numerically stated.

\section{DISCUSSION}

As the two research questions are interrelated and their findings support one another, the discussion will combine the findings of the two questions. An overall conclusion can be drawn from the results of this analysis that is the two sources under study had a dominant emphasis on the lower- level questions. To clarify whether the two sources under study led equally to the foregoing result, each source was examined by itself.

\section{A. Teachers'Questions}

The analysis revealed that questions asked by teachers included a greater proportion of lower level cognitive questions than those found in Unlock Reading and Writing 1. A percentage of $87.42 \%$ was found as lower- level questions and $12.59 \%$ was found as higher-level questions. Teachers' questions showed an unbalanced distribution of lower- and higher-level questions. The focus of the questions of the teachers is found mainly under the levels of comprehension and knowledge. Synthesis was completely ignored and the level analysis appeared only in ten questions. The order of the thinking levels was as follows: comprehension, knowledge, evaluation, application, and analysis, with synthesis excluded.

\section{B. Second: Unlock Reading and Writing 1}

The analysis revealed that Unlock Reading and Writing showed a greater percentage of higher-level questions than teachers' questions did. A percentage of $29.94 \%$ was noticed as higher-level questions and $70.06 \%$ was categorized as lower-level questions. Opposite to the expectation, the focus was also on the comprehension level on the expense of other levels. Synthesis appeared only in one question of the whole textbook. The convincing thing is that there is much 
focus on the evaluation level. The order of the inclusion of the questions in the six levels was the following: comprehension, evaluation, analysis, knowledge, application, and synthesis.

A comparison of the questioning levels in the two sources reveals significant outcomes. The results show that when moving from teachers' questions to the textbook they teach, a drop is noticed in knowledge and application levels, and a rise is seen in the levels of comprehension, analysis synthesis, and evaluation. It is also noticed that there is a general increase in the percentage of the higher-level questions and a decrease on the parentage of the lower-level questions which sound logical. Hence, the progression of the cognitive level questions among the two sources seems logical.

On the other hand, the predominance of the lower-level thinking questions, and the scarcity of higher-level questions show that the two sources could not provide enough higher-level questions at this level, taking into consideration that the two sources were taught for first English Language year university students. This stage requires higher levels of thinking than in previous stages. This also indicates that there was a tendency in this case to include questions prepared to help students to learn facts rather than to teach them thinking. Thus it can be concluded that the main objectives of the textbook they teachers who teach them were the development of lower-order cognitive skills. Similar to earlier studies (Alul, 2005; Ewies, 2010; Igbaria, 2013; Khosand, 2009; Rawadieh, 1998; Riazi and Mosalanejd, 2010; Sunggingwati, 2003), the current study found that the examined textbooks emphasized lower-level thinking questions.

One reason which could play a part here is that the textbooks studied in the schools had an emphasis on the acquisition of knowledge through memorization rather than creativity of cognitive skills. Furthermore, the secondary examination system in Saudi schools exerts a negative backwash effect where the learners are desired to learn exactly what is included in the textbooks mostly without any changes on the part of the learner. This way, learners are required to memorize the materials and rewrite them on exam sheets.

For this reason, learners are not exposed to analyze, synthesize or evaluate the reading material. Teachers and instructors feel there is no need for going through higher-level skills and they prefer teaching their students lower-level skills. It is likely that textbook developers have also been affected by this phenomenon and have worked in favor of this objective.

\section{CONCLuSION}

Textbook questions and teaches' questioning are regarded as one of the most important activities in EFL classroom. Based on the theory of the cognitive domain, the most important thing is that higher-cognitive levels can promote students' higher-order thinking, because higher-level questions can require students to engage in independent thinking such as problem solving, analyzing and evaluating information. The basic purpose of this study was to analyze teachers' and textbook questions in light of Bloom's Taxonomy (1956), then, these questions were categorized into lower-and higher-levels.

The findings showed that teachers' questions had a high percentage of lower-level questions than higher-level questions. Likewise, the findings showed that Questions in Unlock Reading and Writing 1 had a high percentage of lower-level questions than higher-level questions. An overall conclusion can be drawn from the results of this analysis, that is the majority of teachers' questions in the first year are of the lower-cognitive levels (knowledge, comprehension and application) as they are considered as lower order under bloom's cognitive domain.

\section{PEDAGOGICAL IMPLICATIONS}

This study investigated the levels of questions in the first year of the English Language Department at IMSIU. Therefore, many pedagogical implications can be applied driven from the present study:

1) EFL instructors should consider the need for higher-level questions in planning their lessons by emphasizing this type of questions through discussions, activities and evaluation procedures.

2) EFL instructors in general and those who teach first year at AL-Imam Mohammad Ibn Saud Islamic University in particular should not depend solely on the textbooks as a main source for questions.

3) EFL instructors AL-Imam Mohammad Ibn Saud Islamic University should be familiar with different types of questions in addition to the research findings in order to use higher level questions.

4) It would be useful for teachers and textbooks authors to have training courses on various types and levels of questions and the construction of higher level questions in particular.

\section{SUGGESTIONS FOR FurTher RESEARCH}

The literature reviewed in this study illustrated that questions plays a crucial role in the teaching-learning process. Nevertheless, the investigation revealed that further research needs to be conducted related to questioning. Therefore, the current research attempted to suggest six recommendations for future research:

1- Since this study revealed a deficiency of higher level questions, it is recommended that future research be investigating the cognitive levels in teachers' questions in order to develop their own questioning skills.

2- Future research is needed to discover the relationship between the questions levels and students' response levels.

3- Further research is needed to investigate the impacts of higher level questions on students learning, attitude and achievement. 


\section{REFERENCES}

[1] Alkaleefah, H (1996). Planning for Teaching and the Classroom's Questions: New Methodological Vision. Benghazi, Libya: Dar al-kotob.

[2] Alkhataybeh, M \&Aljafreh, I. (2012). Levels and Types of Questions Raised by EFL Teachers in Southern Al Mazar Directorate of Education. Canadian Social Science, 8. 2 (2012): 21-27.

[3] Alul, F. (2005). Analyzing English textbook questions for the elementary eight grade in Palestine Based on Bloom's Taxonomy of educational goal at its cognitive domain.(Unpublished Master's Thesis, An-Najah National University).

[4] Anderson, R.C., Hiebert, E.H., Scott, J.A., \& Wilkinson, I.A.G. (1985). Becoming a nation of readers: The report of the Commission on Reading. Washington, DC: National Academy of Education, Commission on Education and Public Policy.

[5] Beyer, B. K. (1997). Improving student thinking: a comprehensive approach.Needham Heights, MA: Allyn\& Bacon.

[6] Black, P., \& Harrison, C. (2001). Feedback in questioning and marking: The science teacher's role in formative assessment. School Science Review, 82(301), 55-61.

[7] Bloom, B. S. (1956).Taxonomy of educational objectives. Handbook I: cognitive domain. New York: McKay.

[8] Brualdi, Amy C. (1998). Classroom questions. ERIC Clearinghouse on Assessment and Evaluation, Washington DC; ERIC Clearinghouse on Assessment and Evaluation.

[9] Chin, C. (2004). Questioning students in ways that encourage thinking. Teaching Science, 50(4), 16-21.

[10] Chin, C. 2006. Classroom interaction in science: teacher questioning and feedback to students' responses. International Journal of Science Education, 28(11), 1315-1346.

[11] Costa, A. L., \& Lowery, L. F. (1989).Techniques for teaching thinking.Pacific Grove, CA: Midwest.

[12] Dewey, J. (1933). How we think: A restatement of the relation o f reflective thinking to the educative processes. Boston: Pearson Education, Inc. Boston: Heath and company

[13] Elijah, D., \& Legenza, A. (1978).A comprehension Taxonomy for teachers. Reading Improvement, 73(1), 28-32.

[14] Gall, M. D. (1984). Synthesis of research on teachers' questioning. Education Leadership, 42(3), 40-47.

[15] Hunkins, Francis P. (1995). Teaching Thinking through Effective Questioning. Boston: Christopher-Gordon.

[16] Khan, w., \&Inamullah, H. (2011). A Study of lower-order and higher-order Questions at secondary level. Asian social science. Vol.7, No,9, 149- 157

[17] McTighe, J. (1985).Teaching for thinking, of thinking, and about thinking. School, 33(2), 1-6.

[18] Newton .B. (1978). Theoretical bases for higher cognitive questioning: An avenue to critical thinking. Education. 89 (3).286291.

[19] Paul, R., \& Elder, E. (2001). How to improve student learning. Santa Rosa, CA: The Foundation for Critical Thinking

[20] Sardareh, S. \&Saad, M. (2013). Malaysian Primary School ESL Teachers' Questions during Assessment for Learning. Canadian center if science and Educations.

[21] Scott. A. (2015). Unlock Level 1; Reading and Writing Skills. Cambridge; CUP.

[22] Shen, P. \&Yodkhumlue, B. (2012). A Case Study of Teachers' Questioning and Students' Critical Thinking in college EFL Reading Classroom. International journal of English Linguistics.2 (1); 199- 206.

[23] Swartz, R. J., \& Perkins, D.N. (1989). Teaching thinking: Issues and approaches. PacificGrove, CA: Midwest.

[24] Tan, Z. (2007). Questioning in Chinese University EL Classrooms: What Lies Beyond It?. RELC Journal, 38(1), $87-103$.

[25] Toni, A. \&Parse, F. (2013). The Status of Teacher's Questions and Students' Responses: The Case of an EFL Class. Journal of Language Teaching and Resarch.4 (3), pp.564-569, May.

[26] Wilen.W. (1991). Questioning Skills for Teachers.3rd ed. Washinton. D.C.: National Education Publication.

Abdulaziz Ibrahim S. Alnofal is an assistant professor of English Linguistics. He is teaching English linguistics courses for graduate and undergraduate students in the English Language Department at Imam Mohammad Ibn Saud Islamic University-Riyadh, Saudi Arabia. His research interests include Intercultural Communication, Teaching Writing, Language Acquisition, Discourse Analysis. 